\title{
Performance Analysis at Link Level, for the Next-Generation 802.11N Wi-Fi Channel
}

\author{
Análisis del Desempeño a Nivel de Enlace, para el canal Wi-Fi 802.11N de Siguiente Generación
}

\author{
José Arturo Lagos Sandoval ${ }^{1 *}$, Stephanne Rodríguez Bejarano ${ }^{1}$, Mónica Barragán Vera ${ }^{1}$ \\ ${ }^{1}$ Universidad Militar Nueva Granada, Bogotá, Colombia
}

\begin{abstract}
Speed in data networks is affected significantly when the network supports applications that imply real-time data transmission. This degradation is given precisely by the amount of information used in these types of applications and by the data fragmentation process required. Due to this degradation of speed over the network, in recent years, data transmission performance has advanced considerably over the physical links to improve the conditions of quality of service over these applications, mainly because the new skills required in the new data structure makes it necessary to analyze some types of performance improvements. A probabilistic-type mathematical analysis is sought to, first, analyze the type of packet delivery by the Wi-Fi technology described in the 802.11 standard and, thus, seek the possibility of increasing the value of the maximum transfer unit on these networks. The project shows that if the channel capacity is the same, but transmission distance changes, the value of the throughput capacity (T/C) ratio will be the same, only changing the propagation time according to changes in distance and it is concluded that the capacity and distance parameters do not affect the $\mathrm{T} / \mathrm{C}$ ratio, evidencing that the bit error rate is the key parameter in this relation.
\end{abstract}

Keywords: Maximum Transfer Unit, Wireless Local Area Network, 802.11n Wi-Fi, Quality of Service, Throughput Capacity, Bit Error Rate.

\section{Resumen}

La velocidad en las redes de datos se ve afectada significativamente cuando la red soporta aplicaciones que implican la transmisión de datos en tiempo real. Esta degradación se da justamente por la cantidad de información que se maneja en este tipo de aplicaciones y por el proceso de fragmentación de datos que requieren. Debido a esta degradación de la velocidad sobre la red, en los últimos años se ha avanzado considerablemente el rendimiento en la transmisión de datos sobre los enlaces físicos con el fin de mejorar las condiciones de calidad de servicio sobre estas aplicaciones, debido principalmente a que las nuevas capacidades que se requieren en la nueva estructura de datos hace que sea necesario analizar algún tipo de mejoras en el rendimiento. Se busca realizar un análisis matemático, de tipo probabilístico, para primero analizar el tipo de entrega de paquetes que realiza la tecnología Wi-Fi descrita en el estándar 802.11 y, de esta manera, buscar la posibilidad de incrementar el valor de la unidad máxima de transferencia, sobre estas redes. El proyecto muestra que si la capacidad del canal es la misma, pero cambia la distancia de transmisión, el valor de la relación T/C será el mismo, sólo cambiando el tiempo de propagación según los cambios en la distancia y se concluye que los parámetros de capacidad y distancia no afectan la relación T/C, dejando ver que el BER es el parámetro clave en esta relación.

Palabras clave: Unidad Máxima de Transferencia, Red Inalámbrica de Área Local, Wi-Fi 802.11n, Calidad de Servicio, Capacidad de Trasmisión, Tasa de Error de Bit.

*Corresponding Author.

E-mail:jose.lagos@unimilitar.edu.co
How to cite: Lagos, J., Rodríguez, S. Barragán M. J., Performance Analysis at Link Level, for the Next-Generation 802.11N Wi-Fi Channel, TECCIENCIA, Vol. 12 No. 22, 73-77, 2017

DOI: http://dx.doi.org/10.18180/tecciencia.2017.22.8 


\section{TECCIENCIA}

\section{Introduction}

In data networks, it is notable that speed is affected significantly when the network supports applications that imply real-time data transmission, like music on demand (MOD), video on demand (VOD), voice IP services (VoIP), videoconference, etc., [1]. This degradation is given precisely because of the amount of information handled in these types of applications and by the data fragmentation process required in these types of apps. Due to this degradation of speed over the network [2] [3], in recent years considerable improvement has been made in the performance of data transmission over the physical links to improve the quality of service (QoS) [1] conditions on these applications, mainly because of the new skills required in the new data structure [4] [5], making it necessary to analyze some types of performance improvements. It is worth noting that until now, according to the research conducted, few studies have been made on the implementation of techniques that permit increasing the maximum transfer unit (MTU) [6].

This document implies the possibility of increasing the MTU in networks with next-generation Wi-Fi 802.11n-type link, without making modifications at software level within the devices that make up the network, but conducting an analysis of the physical parameters, like the bit error rate (BER) [7], and, thus, study the possibility of how to improve a network's performance by increasing the MTU [8].

\section{Materials and Methods}

Environment. Wireless devices sharing the same protocol on the MAC header follow the IEEE 802.11 standard [9], of wireless local area network (WLAN); these devices are governed by different standards for the physical layer. For example, 802.11a, 802.11b, 802.11g, 802.11n, etc., all these standards support multirate transmissions [11]. Current research is significant to improve the performance of these networks, basically due to factors, like [12], multimedia applications, applications which are now more sensitive to the quality of service and to the inherent and internal deficiencies of wireless communications, such as scarce broadband resources and time variables of the channel conditions [13].

1) $802.11 \mathrm{n}$ standard. We will base our work on the $802.11 \mathrm{n}$ standard, given that it is a recommendation that tests and certifies that the equipment comply with the 802.11 standards related to WLAN, thus, thereafter an analysis was made of the type of control made and the components of the MAC header.

In the first place, the MAC header contains the following components: frame control, duration, address and sequence control information, and, for QoS of data frames, QoS of control information. In the second place, a variable longitude (frame body), which includes specific information for the type of frame and the subtype and, finally, FCS. The MAC header format includes a set of fields produced in a fixed order and all the frames.

Figure 1 represents the general format of the MAC frame. The first three fields of the control frame, Frame Control, Duration/ID, and Address 1, and the last field (FCS) constitute the minimum frame format and are present in all the frames, including the types and subtypes reserved. The Address of fields 2, 3, Sequence control, Address 4, QoS Control, HT control, and frame body are present only in certain types of frames and subtypes. The bodily structure field is of variable size.

Table 1. MAC frame format [10].

\begin{tabular}{|c|c|c|c|c|c|c|c|c|c|}
\hline \multicolumn{1}{|c|}{ Octets } & 6 & 6 & 2 & 4 & $0-9955$ & 4 \\
\hline $\begin{array}{c}\text { Frame } \\
\text { Control }\end{array}$ & Duration/ID & Address 1 & Address 2 & Address 3 & $\begin{array}{c}\text { Sequence } \\
\text { Control }\end{array}$ & Address 4 & $\begin{array}{c}\text { QoS } \\
\text { Control }\end{array}$ & $\begin{array}{c}\text { HT } \\
\text { Control }\end{array}$ & $\begin{array}{c}\text { Frame } \\
\text { Body }\end{array}$ \\
FCS
\end{tabular}

Table 2 Header, Control frame [13].

\begin{tabular}{|c|c|c|c|c|c|c|c|c|c|c|}
\hline B0-B1 & B2-B3 & B4-B7 & B8 & B9 & B10 & B11 & B12 & B13 & B14 & B15 \\
\hline $\begin{array}{c}\text { Protocol } \\
\text { version }\end{array}$ & Type & Subtype & $\begin{array}{c}\text { To } \\
\text { DS }\end{array}$ & $\begin{array}{c}\text { From } \\
\text { DS }\end{array}$ & $\begin{array}{c}\text { More } \\
\text { Frag }\end{array}$ & Retry & $\begin{array}{c}\text { Pwr. } \\
\text { Mgt. }\end{array}$ & $\begin{array}{c}\text { More } \\
\text { Data }\end{array}$ & $\begin{array}{c}\text { Protected } \\
\text { Frame }\end{array}$ & \begin{tabular}{c} 
Order \\
\hline \multicolumn{1}{|c|}{ Bits }
\end{tabular} \\
\hline \multicolumn{2}{|c|}{} & 2 & 4 & 1 & 1 & 1 & 1 & 1 & 1 & 1 \\
\hline
\end{tabular}




\section{TECCIENCIA}

The maximum size of the frame body is determined by the maximum size MSDU (2304 octets) plus any security encapsulation overload, Table 1 [14].

The first field of the MAC header is the frame control, which consists of the following subfields, Table 2, Protocol Version, Type, Subtype, To DS, From DS, More Fragments, Retry, Power Management, More Data, Protected Frame, and Order.

The header function (Table 2) is that of identifying fields by type and subtype, where the type field is 2 bits long and the subtype field is 4 bits long. Three types of frames are available: control, data, and management.

In the data frames, the most significant bit (MSB) of subtype is b7, and is defined as QoS subfield, considered of importance because this subfield describes the quality of service, which allows us to know the situation of the data frame, for example, Table No. 3 describes how it functions around this field [15]. Change of the value type bits will depend on what has to be done, whether we receive an ack (acknowledgment) or a nack (no acknowledgment); likewise, for the value of the subtype. The field of QoS control is present in all data frames, so this field is established in 1 (assume the value of 1), this information allows knowing the field description.

\subsection{Statistical analysis}

The probability of getting a frame error in the receptor is $P$, so the probability of getting a correct reception is $(1-P)$. The field length in the packet frame is $L d$. The length of the packet frame control system is $L c$. The probability of bit error, BER, refers to the amount of errors that can be found statistically in a channel [3]. Basically, due to the very characteristics of the channels, like the signal-to-noise ratio (SNR). Assuming the BER, as the probability of bit error, that is, that at least one bit shows error within the frame, then the probability of no error in the frame is the probability of the BER elevated to the total size of the frame, and it is calculated according to the following equation

$$
P=1-(1-B E R)^{(L d+L c)}
$$

Based on Table 1, and aware that the size of the control field is 320 bits, it is taken on a fixed value, while the size of the data changes. To conduct the simulation of the channel efficiency, it is important to bear in mind the following variables [11]: Transmission Capacity is C; time of propagation, $T p$, which depends on the velocity of propagation, $V p$, where $V p=V_{c} / E r$, speed of light and relative permittivity of air and distance $X$, thus, $T p=X / V p$, the time required to transmit a frame $T i, T i=(L d+L c) / C$; time out, Tout; total time, $T t$, which is equal to $T t=T i+T o u t$, $a$ is a standardized parameter that represents the time out in an equal interval $a=T t / T i$, applying the following equation:

$$
\frac{T}{C}=\left(\frac{L d}{L d+L c}\right)\left[\frac{(1-P)}{1+(a-1) P}\right]
$$

\section{Results}

For the simulations, we used MATLAB. In the first place, the link will be simulated with the parameters listed in Table 4. Transmission capacity will vary, while distance remains constant. Each line in Figure 1 represents a different value of BER.

Table 3 Valid type and combinations of subtype.

\begin{tabular}{|l|l|l|l|}
\hline $\begin{array}{l}\text { Type } \\
\text { value } \\
\text { b3 b2 }\end{array}$ & $\begin{array}{l}\text { Type } \\
\text { Description }\end{array}$ & $\begin{array}{l}\text { Subtype } \\
\text { value b7 } \\
\text { b6 b5 b4 }\end{array}$ & $\begin{array}{l}\text { Subtype } \\
\text { Description }\end{array}$ \\
\hline 01 & Control & 1101 & ACK \\
\hline 00 & Management & 1110 & NOT-ACK \\
\hline
\end{tabular}

Table 4 Simulation parameters.

\begin{tabular}{|c|c|c|c|}
\hline Channel & Velocity & Distance & B. E. R. \\
\hline 1. C & $150 \mathrm{Mbps}$ & $1 \mathrm{~km}$ & $1 \mathrm{e}-4,1 \mathrm{e}-5,1 \mathrm{e}-6,1 \mathrm{e}-7$ \\
\hline 2. C & $300 \mathrm{Mbps}$ & $1 \mathrm{~km}$ & $1 \mathrm{e}-4,1 \mathrm{e}-5,1 \mathrm{e}-6,1 \mathrm{e}-7$ \\
\hline 3. C & $600 \mathrm{Mbps}$ & $1 \mathrm{~km}$ & $1 \mathrm{e}-4,1 \mathrm{e}-5,1 \mathrm{e}-6,1 \mathrm{e}-7$ \\
\hline
\end{tabular}

Figure 1 is a summary of the three situations evaluated because they always behaved similarly, yielding the same values in the $x$ axis corresponding to bits; these values were divided over eight to obtain the value in Bytes and compare to the values currently available for wireless transmissions, as evidenced in Figure 2 [7]. In addition, the simulation of the link will be conducted with the parameters in Table 5 . Thus, distance will vary, while capacity remains constant; each line on the graphic represents a different value of BER.

Table 5 Simulation parameters for varying distances.

\begin{tabular}{|c|c|c|c|}
\hline Channel & Velocity & Distance & B. E. R \\
\hline 1. C & $300 \mathrm{Mbps}$ & $5 \mathrm{~km}$ & $1 \mathrm{e}-4,1 \mathrm{e}-5,1 \mathrm{e}-6,1 \mathrm{e}-7$ \\
\hline 2. C & $300 \mathrm{Mbps}$ & $25 \mathrm{~km}$ & $1 \mathrm{e}-4,1 \mathrm{e}-5,1 \mathrm{e}-6,1 \mathrm{e}-7$ \\
\hline 3. C & $300 \mathrm{Mbps}$ & $50 \mathrm{~km}$ & $1 \mathrm{e}-4,1 \mathrm{e}-5,1 \mathrm{e}-6,1 \mathrm{e}-7$ \\
\hline 4. C & $300 \mathrm{Mbps}$ & $100 \mathrm{~km}$ & $1 \mathrm{e}-4,1 \mathrm{e}-5,1 \mathrm{e}-6,1 \mathrm{e}-7$ \\
\hline
\end{tabular}




\section{TECCIENCIA}

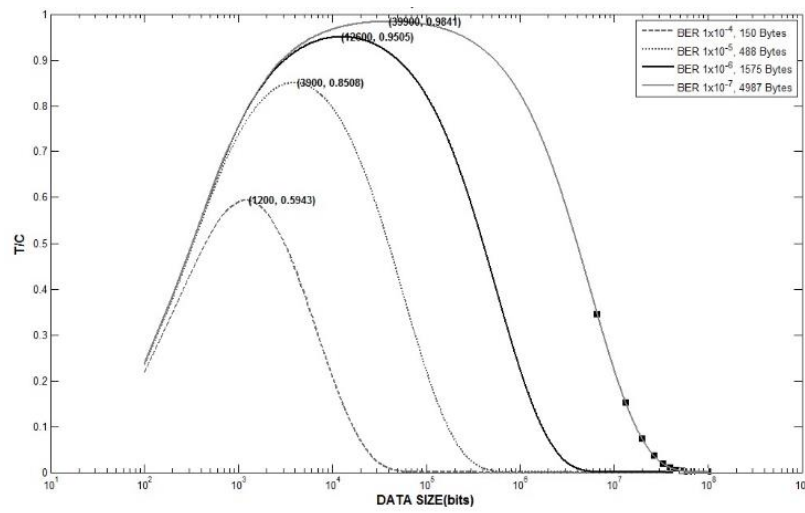

Figure 1 Capacity of $150 \mathrm{Mbps}$ Vs. Distance of $1 \mathrm{~km}$.

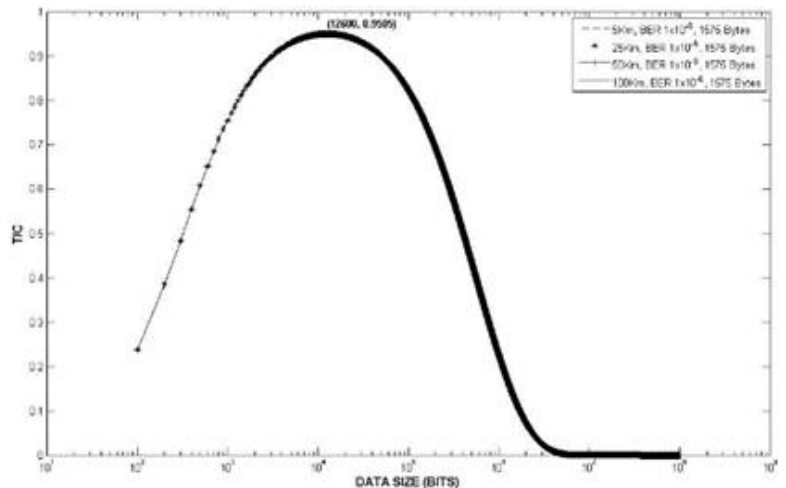

Figure 2 Capacity of $300 \mathrm{Mbps}$ Vs. Distance of $25 \mathrm{~km}$.

Figure 3 shows that as with the previous case, the change occurs in the data (bits). If the capacity is the same, but transmission distance varies, the final results demonstrate that the values in the throughput capacity $(\mathrm{T} / \mathrm{C})$ ratio are the same, the only thing that varies is the propagation time due to changes in distance.

As noted above, the capacity and distance variables do not alter the results in any way, upon evaluating the situation of the constant channel and variable distance, we obtained the results shown ahead, reaffirming no dependence on distance (Table 6).

Table 6 Results of the simulation with constant capacity.

\begin{tabular}{|c|c|c|}
\hline Capacity & Distance & Ber \\
\hline $300 \mathrm{Mbps}$ & $5 \mathrm{~km}$ & $1 \mathrm{e}-6$ \\
\hline $300 \mathrm{Mbps}$ & $25 \mathrm{~km}$ & $1 \mathrm{e}-6$ \\
\hline $300 \mathrm{Mbps}$ & $50 \mathrm{~km}$ & $1 \mathrm{e}-6$ \\
\hline $300 \mathrm{Mbps}$ & $100 \mathrm{~km}$ & $1 \mathrm{e}-6$ \\
\hline
\end{tabular}

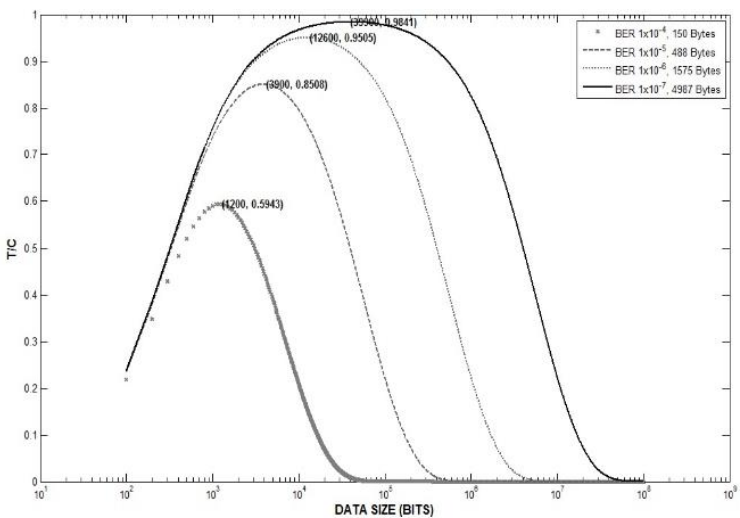

Figure 3 Capacity of 300 Mbps Vs. Distance of $50 \mathrm{~km}$.

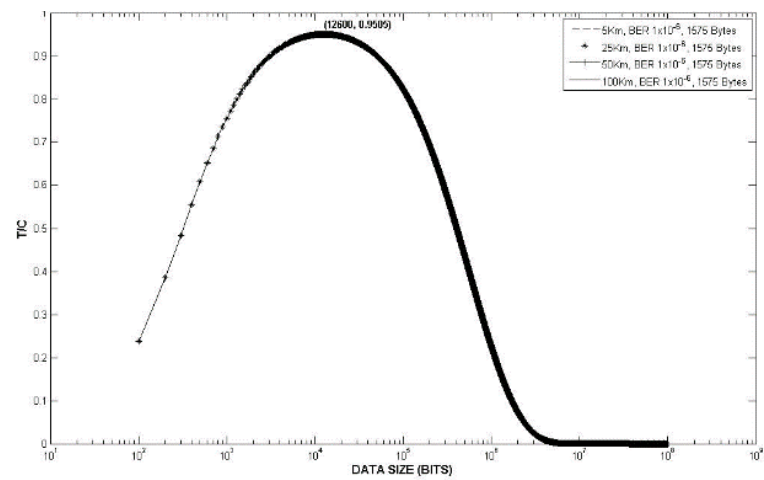

Figure 4 Capacity of 300 Mbps Vs. Distance of $50 \mathrm{~km}$.

\section{Conclusions}

The results show that the channel capacity is not a variable that somehow determines the maximum bit value in the transmission, given that the time to place the frame in the channel depends on the header size, (data and control) and on the throughput capacity $(T i=(L c+L d) / C)$. Indicating that $T i$ will always tend to zero.

When having the same BER value and the same capacity, in spite of varying the distance, the values of the T/C ratio are the same for all distances, evidencing that the BER is the most important parameter in the $\mathrm{T} / \mathrm{C}$ ratio.

The simulation where the MATLAB tool was not used permits determining parameters and their changes, without need to intervene directly on the frame or its components, speeding up changes and improvements in communication systems. 


\section{TECCIENCIA}

\section{References}

[1] "IEEE standard for information technology-telecomunications and information exchange between systems-local and metropolitan area networks-specific requirements - part 11: Wireless LAN medium access control (mac) and physical layer (phy) specifications", IEEE Std 802.11-2007 (Revision of IEEE Std 802.11-1999), pp. C1 $1184,122007$.

[2] O. J. M. Torres y J. B. Velandia, «Monitoring, management and topological display device using wireless network managed clients,» Tecciecnia, vol. 8, $\mathrm{n}^{\circ}$ 15, pp. 93-100, 2013.

[3] "IEEE standard for information technology-telecomunications and information exchange between systems-local and metropolitan are networks-specific requirements - part 11: Wireless LAN medium access control (mac) and physical layer (phy) specifications amendment 5: Enhancements for higher thoughput", IEEE Std 802.11n (Amendment to IEEE Std 802.11-2007 as amended by IEEE Std 802.11k-2008, IEEE Std 802.11r-2008, IEEE Std 802.11y-2008, and IEEE Std 802.11w-2009, pp. C1 - 502, 292009.

[4] N. M. E. Amr M. Otefa1 and E. A. Sourour. (2007), "Performance analysis of $802.11 \mathrm{n}$ wireless LAN physical layer", Electrical Engineering in the Faculty of Engineering, Alexandria University, Egypt, vol. 17, no. 3, pp. 487 - 503, [Online]. Available: http://www.sciencedirect.com/science/article/aaap/S1569190X0800 $\underline{169 X}$.

[5] L. S. G. Monsalve, «Experimento de recuperación de información usando las medidas de simil,» Tecciencia, vol. 6, n 12, pp. 14-24, 2012 .

[6] L. Zhang, Y. J. Cheng, and X. Zhou. (2009), "Rate avalanche: Effects on the performance of multi-rate 802.11 wireless networks", Simulations Modelling Practice and Theory, V. 17, No. 3, pp. $487-$ 503.

[7] T. S. M. Melody Moh and K. Chan. (2010), "Error-sensitive adaptive frame aggregation in 802.11n WLAN", Deparment of Computer Science, San Jose State University, San Jose, CA 95192-0249 USA, [Online].

Available: http://www.sciencedirect/science/article/pii/S143484112221100991

[8] P. Narayan, S. Lutui. (2011), "Internet multimedia services architecture and application (imsaa)", 2010 IEEE 4th International conference on vol. 17, no. 3, pp. 487-503, [Online]. Available: http://www.ieeexplore.ieee.org/xpl/mostRecent00Issue.jsp?punumb er $=5724109$.

[9] S. C. S. K. L. o. N. Peng Zhang, Hongbo Wang and S. Technology. (2013), "Shrinking MTU to improve fairness amoung TCP flows in data center networks", Beijing University of Posts and Telecommunications systems". [Online]. Available: http://www.sciencedirect/science/article/pii/S19998569190X08001 69X.

[10] A. M. J. B. C. Reviriego, P.; Sánchez-Macian. (2011), "Interne multimedia services architecture and applicatio (imsaa)" [Online]. Available:

http://www.ieeexplore.ieee.org/xpl/mostReceoontIssue.jsp?punumb er $=561880070$

[11] M. Schwartz. (1994)., Redes de telecomunicaciones. Protocolos, modelado y análisis. Addison Wesley IBEROAMERICANA.

[12] Y. Xu and K. Wang. (2008), "Channel correlated channel for 802.11 system", Institute of Information and Communication
Engineering, Zhejiang University, Hangzhou, V. 17, No. 3, pp. 487 -503 .

[13] Y. X. Weiqian Weng and K. Wang. (2007), "Channel estimation in correlated channel for 802.11n system", Institute of Information and Communication Engineering, Zhejiang University. [Online] Available:

http://www.sciencedirect/science/article/pii/S14348411888002901.

[14] C. Y. M. H. Y. Wei. (2009), “IEEE 802.11n MAC enhancement and performance evaluation", Springer Science + Business Media, LLC 2008, vol. 17, no. 3, pp. 487-503. [Online]. Available: http://www.sciencedirect/science/article/pii/S1569100090X080016 $9 \mathrm{X}$

[15] F. Heereman, W. Joseph, E. Tenghe, D. Plets, L. Verloock, and L, Martens. (2011), "Path loss model and prediction of range, power and throughput for $802.11 \mathrm{n}$ in large conference rooms", AEU International Journal of Electronics and Communications. [Online] Available:

http://www.sciencedirect.com/science/article/pii/S14348411110029 01.

[16] IEEE, Std 802.11, capítulo 2 [Online]. Available: http://bibing.us.es/proyectos/abreproy/11306/fichero/TEORIA\%25 2F07+-+Capitulo+2.pdf 